\title{
A Novel Shape Compact Antenna for Ultrawideband Applications
}

\author{
Saad Hassan Kiani $\left(\mathbb{D},{ }^{1}\right.$ Xin Cheng Ren $(\mathbb{D})^{2}$ Muhammad Rizwan Anjum $\left(\mathbb{D},{ }^{3}\right.$ \\ Khalid Mahmood (D), ${ }^{4}$ Haider Ali (D), ${ }^{5}$ Naveed Jan (D), ${ }^{5}$ Muhammad Adil Bashir (D), \\ and Muhammad Abbas Khan ${ }^{7}{ }^{7}$
}

\author{
${ }^{1}$ Department of Electrical Engineering, City University of Science and Information Technology, Peshawar 25000, Pakistan \\ ${ }^{2}$ School of Physics and Electronic Information, Yanan University, Yanan 761000, China \\ ${ }^{3}$ Department of Electronic Engineering, The Islamia University of Bahawalpur, Bahawalpur 63100, Pakistan \\ ${ }^{4}$ Department of Electrical Engineering, Abasyn University, Peshawar 25000, Pakistan \\ ${ }^{5}$ Department of Electrical and Electronics Engineering Technology, University of Technology Nowshera, Nowshera, Pakistan \\ ${ }^{6}$ Electrical Engineering Department, Bahauddin Zakariya University, Multan, Pakistan \\ ${ }^{7}$ Department of Electrical Engineering, Balochistan University of Information Technology, Engineering and \\ Management Sciences, Quetta, Pakistan
}

Correspondence should be addressed to Xin Cheng Ren; xchren@yau.edu.cn

Received 17 September 2021; Accepted 28 September 2021; Published 6 October 2021

Academic Editor: Muhammad Inam Abbasi

Copyright (c) 2021 Saad Hassan Kiani et al. This is an open access article distributed under the Creative Commons Attribution License, which permits unrestricted use, distribution, and reproduction in any medium, provided the original work is properly cited.

\begin{abstract}
Nowadays, more attention has been given into ultrawideband by dint of its extraordinary features over narrowband communication systems. This study presents a novel compact with tilted square frames shape antenna with partial ground plane. The proposed antenna is printed on commercially available Fr4 substrate with relative thickness of $1.6 \mathrm{~mm}$. The antenna has compact dimensions of $14 \times 18 \mathrm{~mm}^{2}$ with bandwidth ranging from 3.3 to $11.5 \mathrm{GHz}$. The peak gain obtained is $1.4 \mathrm{dBi}$ with omnidirectional radiation characteristics throughout the entire bandwidth. The proposed antenna is fabricated, and the developed prototype measured results, which well agree with simulated results. With the performance parameters obtained and the well agreed measured results, the proposed antenna is well suitable for Wi-Fi, ISM, and UWB applications.
\end{abstract}

\section{Introduction}

The rapid progress of wireless communication systems has emerged the need of wideband antenna, since they cover majority of applications. After the announcement of ultrawide band (UWB) by federal services commission, several antennas designs have been proposed in order to be deployed on the industrial scale. With low energy consumption, better channel capacity characteristics within the partial range, unmanned vehicles (UAVs), and body area networks (WBANs) [1, 2], the UWB antennas are emerging as most promising candidates for future wireless communication systems $[3,4]$. UWB antenna role as compared to the conventional narrowband antenna system is unique and vital. Also, printed antenna technology light weight and lowcost fabrication characteristics as compared to conventional antenna structures provide quick and reliable wireless communication access. In published literature, several antennas have been reported on UWB technology [5-10].

In literature, several wide and ultrawideband antenna structures have been reported. With a size of $121 \times 314 \mathrm{~mm}^{2}$, a wide band antenna is reported in [5] with bandwidth of approximately $4.6 \mathrm{GHz}$ ranging from 3.4 to $8 \mathrm{GHz}$. The shape of the antenna comprises a leaf structure with partial ground plane. The proposed antenna is well developed but is difficult to integrate in RF circuits due to its unconventional size. Similarly, in [6], an UWB is proposed with the total size of $31 \times 23 \mathrm{~mm}^{2}$, having bandwidth characteristics ranging from 3 to almost $15 \mathrm{GHz}$. The antenna is small in size, but the gain variations are quite big. In [7], a monopole antenna is presented with elliptical slot rings. With nearly gain up to $3.5 \mathrm{dBi}$, the antenna exhibits good flat gain near the entire resonating spectrum, but the size of antenna is quite large up to $100 \times 100 \mathrm{~mm}^{2}$. 
A miniaturized UWB antenna with dimensions of $9.11 \times 10.8 \mathrm{~mm}$ is proposed in [8] with an operating bandwidth of at least $1 \mathrm{GHz}$ around a centre frequency of $4 \mathrm{GHz}$ for implantable applications. The M-shaped antenna resonating with $5600 \mathrm{MHz}$ bandwidth ranging from 3.25 to $8 \mathrm{GHz}$ is covered in [9], with large size of $100 \times 160 \mathrm{~mm}^{2}$. The $\mathrm{V}$ shape antenna with truncated ground plane is presented at [10]; the size of the antenna is $28 \times 36 \mathrm{~mm}$, and the gain varies between 0.5 and $2 \mathrm{~dB}$. In [11-14], several antennas have been developed for UWB applications, but they come in large sizes. In [14], the wideband response of $8 \mathrm{GHz}$ has been reported, but the size of the antenna is $50 \times 50 \mathrm{~mm}$. Such type of large sizes makes antenna difficult to embed in modern RF devices. A compact antenna with single notch characteristics has been reported in [15] using split ring slots. The size of the antenna is $23 \times 20 \mathrm{~mm}$. Similarly, in [16, 17], UWB antennas are proposed with band notch characteristics with approximate size of $30 \times 34 \mathrm{~mm}^{2}$ and $32 \times 36 \mathrm{~mm}^{2}$. A multilayered compact 3D antenna in [18] exhibits wideband impedance characteristics of $40 \%$. The multilayer structure makes it complex to fabricate. A ring loaded circular patch in [19] covers the bandwidth from 4.27 to $8.72 \mathrm{GHz}$.

In the reported works, the UWB structures are found to be at either exceptionally large or small with gain variations. The modern RF communication systems require the antennas to be compact in size, so that they could easily be embedded. Therefore, this research presents a novel UWB antenna with a compact size of $225 \mathrm{~mm}^{2}$ and flat gain of $1.2-1.4 \mathrm{dBi}$. The proposed antenna is well compact in size as compared to the published literature and is suitable for next generation UWB systems.

\section{Antenna Design}

The proposed antenna is designed on commercially available FR4 substrate with relative permittivity of 4.3 and loss tangent of 0.02 . The overall dimension of the proposed antenna is $18 \times 14 \times 1.6 \mathrm{~mm}^{3}$. Figure 1 shows the overall view and dimension of the proposed antenna.

The printed monopole UWB antenna has been transformed in a sequence of steps. The aim of the proposed antenna was to resonate at ultrawideband range. Figure 2 shows the step-by-step design development of the proposed antenna. In stage 1 , a square frame tilted at $45^{\circ}$ with half ground plane was introduced. In this stage, the resonance response achieved was almost $1.5 \mathrm{GHz}$ ranging from 7 to $8.5 \mathrm{GHz}$. The second stage in the evolution introduced a square slot on the ground plane. The ground slot improved the reflection coefficient response up to $2.5 \mathrm{GHz}$. Then, the introduction of the square frames at $2.5 \mathrm{~mm}$ distance resulted in the proposed design, in which the resonance frequency shifted from 3.2 to $11.6 \mathrm{GHz}$. Also, the design showed the minimum reflection coefficient value of $-29 \mathrm{~dB}$ at $6.3 \mathrm{GHz}$ frequency.

2.1. Parametric Analysis. The proposed antenna has been tuned in number of steps to achieve the desired frequency band response. There were several parameters such as ground slot and transmission line length and width that involved in constant analysis. Figure 3 shows the complete parametric analysis of our proposed design.

In Figure 3(a), it can be seen that the effect of the ground slot on the resonance response of the antenna is captivating. As the ground slot increases in size, the resonance response gets wider and the higher frequency response gets generated. This is limited to a certain threshold value of $4.25 \mathrm{~mm}$, which exhibits the desired frequency response of the proposed antenna. After this point, the antenna starts exhibiting the dual band nature.

The distance between the square frames has been set at $2.5 \mathrm{~mm}$. In Figure $3(\mathrm{~b})$, the effect of the antenna on resonance has been observed. By looking at the figure, it is obvious that the increasing distance causes the antenna to be more focused in lower band and the response of the bandwidth decreases. Similarly, the feed length of the proposed antenna shows that with lower values, its impedance mismatches and the response of the antenna diminishes. At $12 \mathrm{~mm}$ length, the desired bandwidth is achieved which when further increased causes the bandwidth to abrupt.

\section{Results and Discussion}

This section discusses the results from the fabricated prototype and their comparison with the simulated results. The propose antenna is fabricated using the LPFK machine, and the measured reflection coefficient is found to be in good agreement with the simulated results. Slight variations are found in the measured results, but they can be attributed to the cable losses, connector losses, and random measurement set up losses. Figure 4 shows the fabricated prototype with simulated and measured reflection coefficient.

The performance parameters of the proposed antenna are shown in Figure 5. The peak gain simulated is found to be $1.4 \mathrm{dBi}$, while the measured gain is found to be at $1.389 \mathrm{dBi}$. The efficiency of the proposed antenna ranges from 60 to $68 \%$. The gain is found to be at acceptable levels; since the proposed antenna is compact in size, the gain can be considered on satisfactory levels considering the size of the proposed antenna.

3.1. Radiation Patterns. The radiation patterns of the antenna both simulated and measured in phi 90 and theta 90 plane are shown in Figure 6. The radiation patterns of the proposed antenna were measured in an anechoic chamber. The antenna showed well-measured radiation patterns, and it can be observed that antenna exhibits an omnidirectional response. The radiation patterns measured are from 4.5, 5.5, 6, and $7 \mathrm{GHz}$. From the figure, it can be observed that the radiation patterns are stable across the entire bandwidth. The simulated and measured results slight variations can be due to the measurement set up errors. In phi 90 plane, the antenna exhibits a directional response at some frequency points. Overall, the 


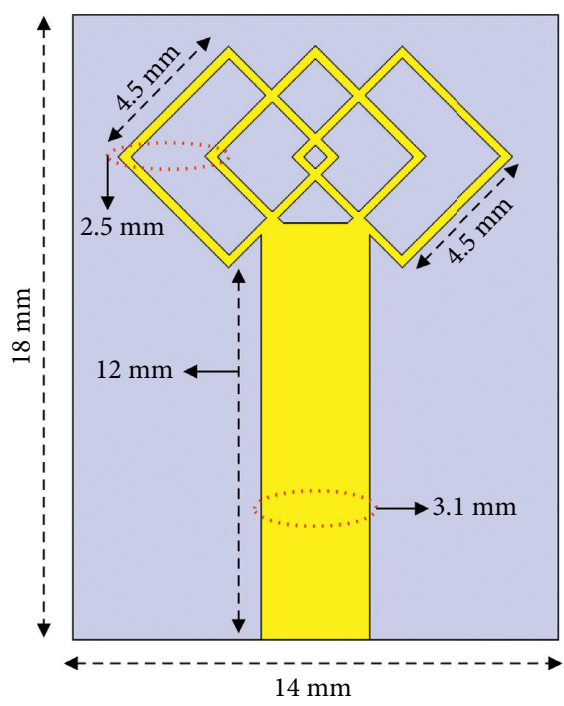

(a)

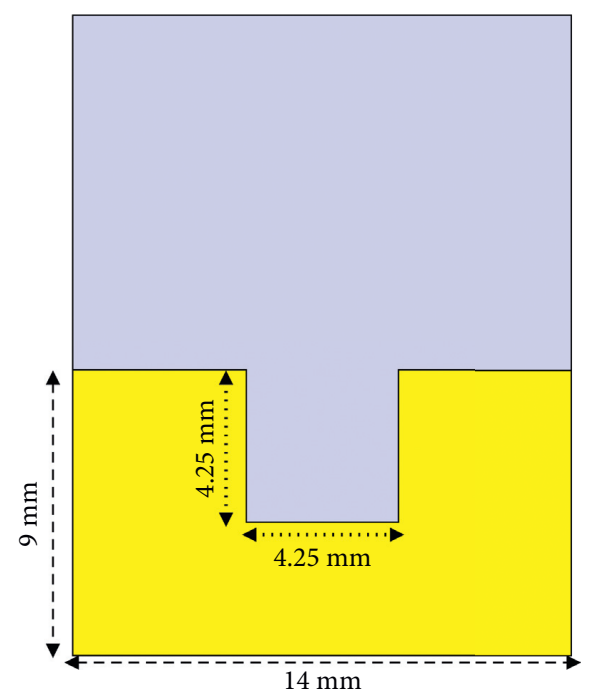

(b)

Figure 1: Proposed antenna design. (a) Front. (b) Back.

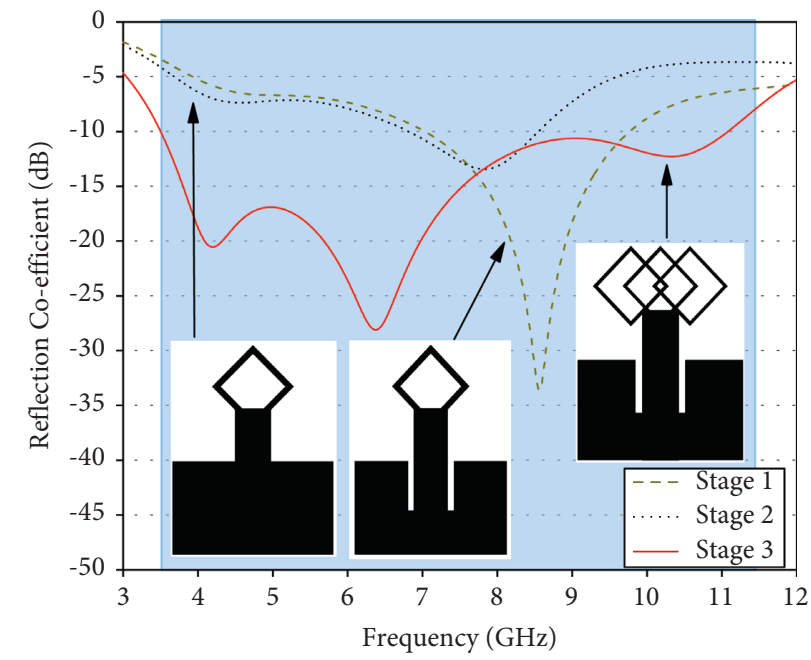

Figure 2: Design evolution of the proposed antenna.

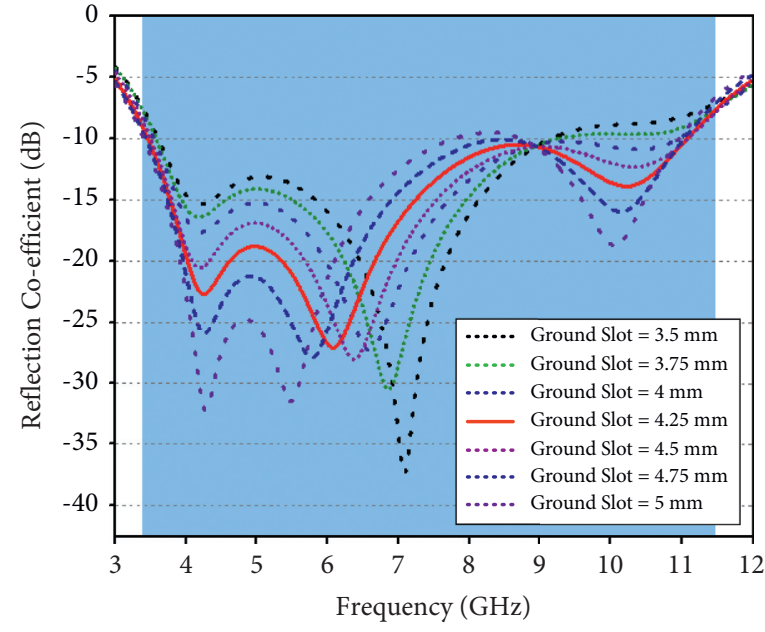

(a)

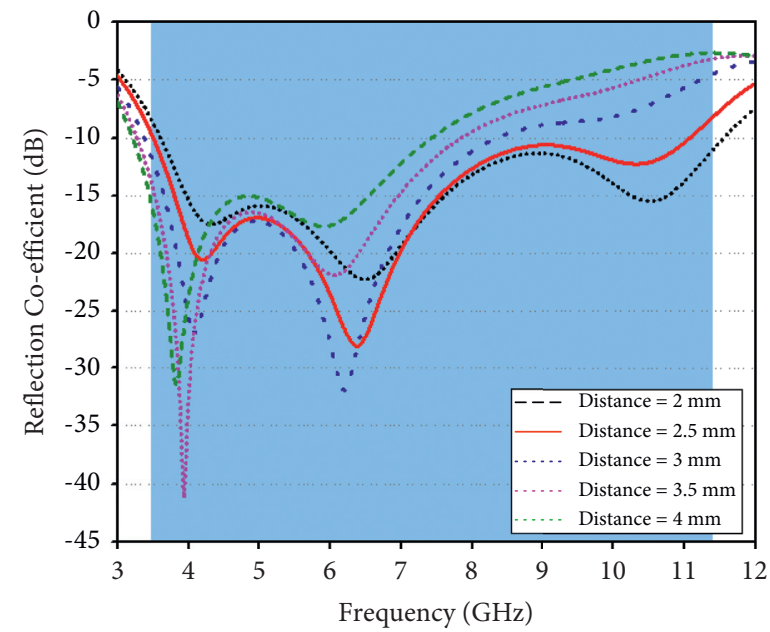

(b)

FIgure 3: Continued. 


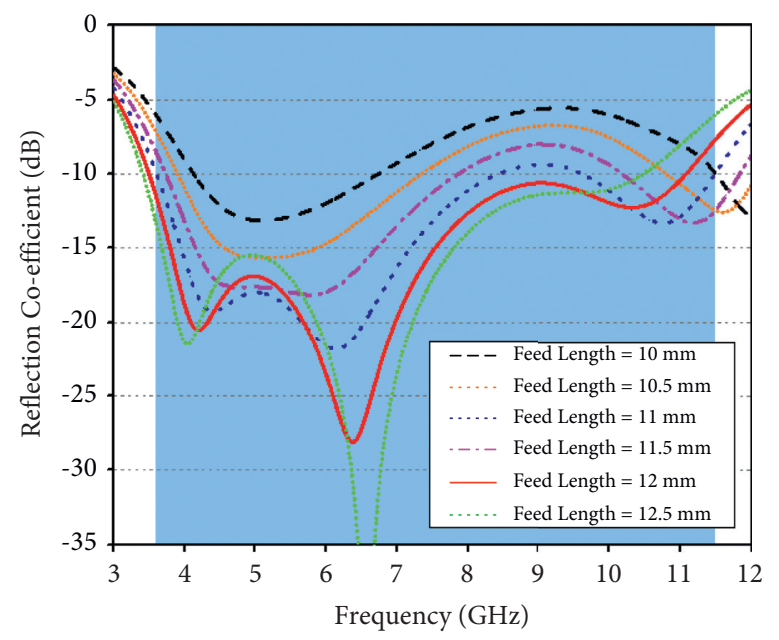

(c)

FIgUre 3: Parametric analysis of the proposed antenna. (a) Ground slot. (b) Distance. (c) Feed length.

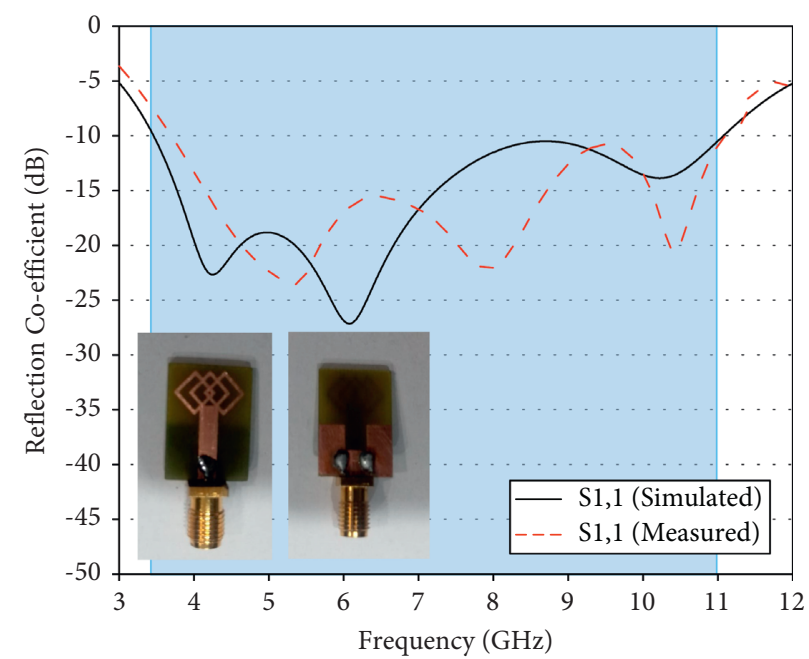

Figure 4: Simulated and measured reflection coefficient.

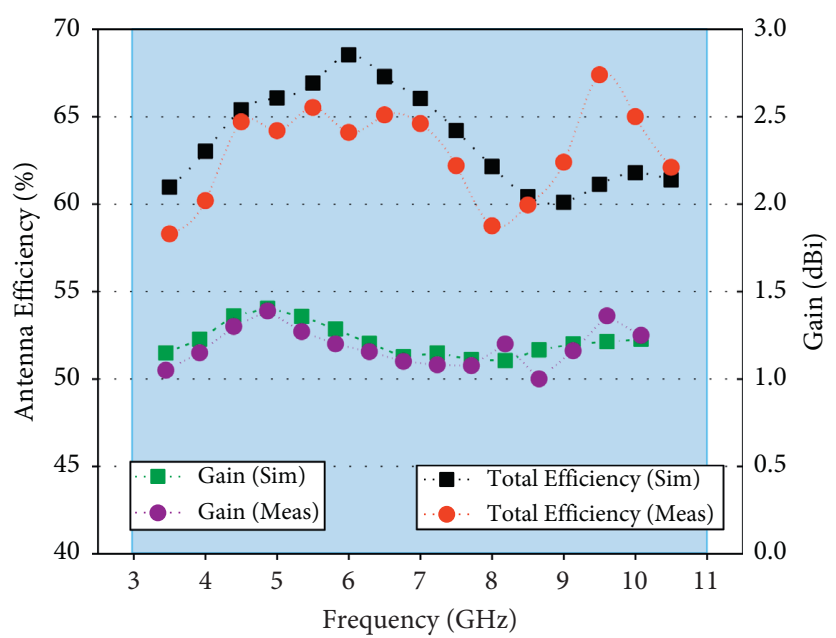

Figure 5: Antenna efficiency and gain parameters. 


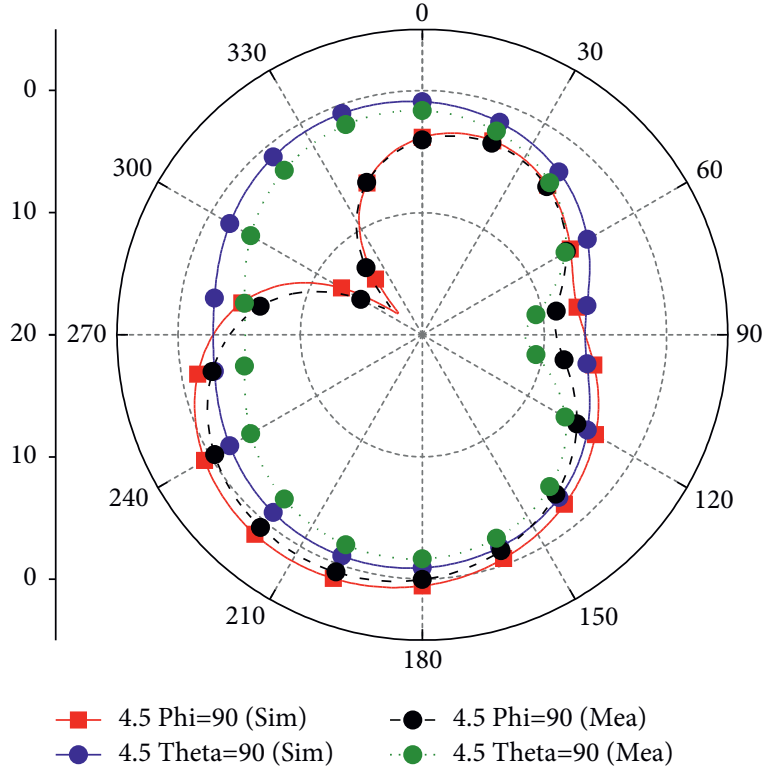

(a)

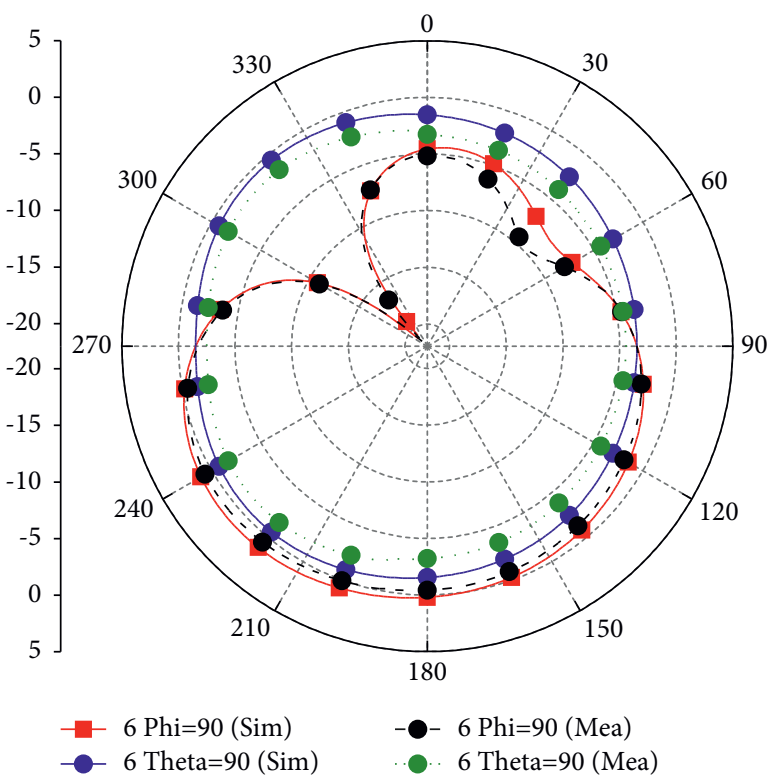

(c)

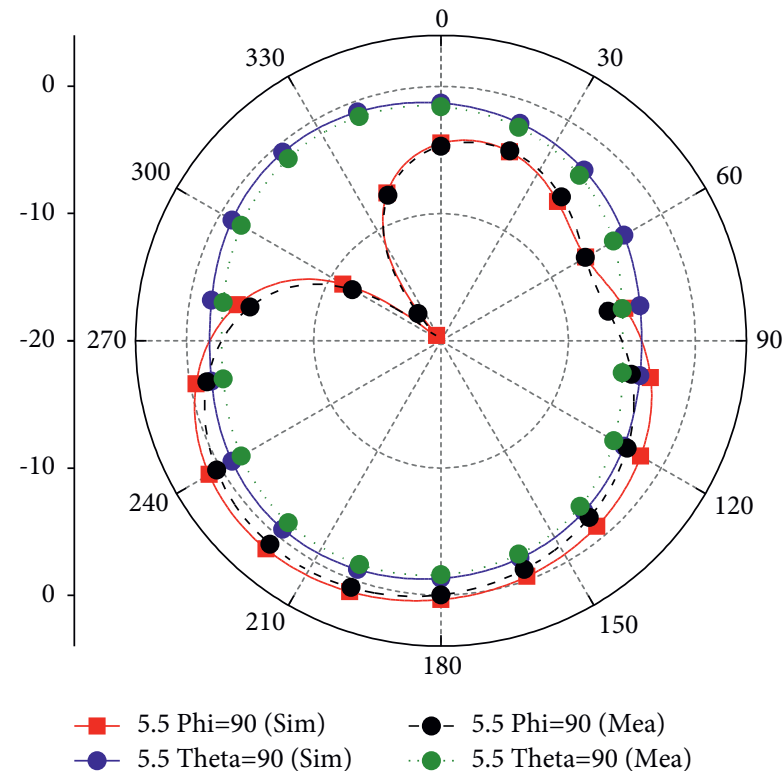

(b)

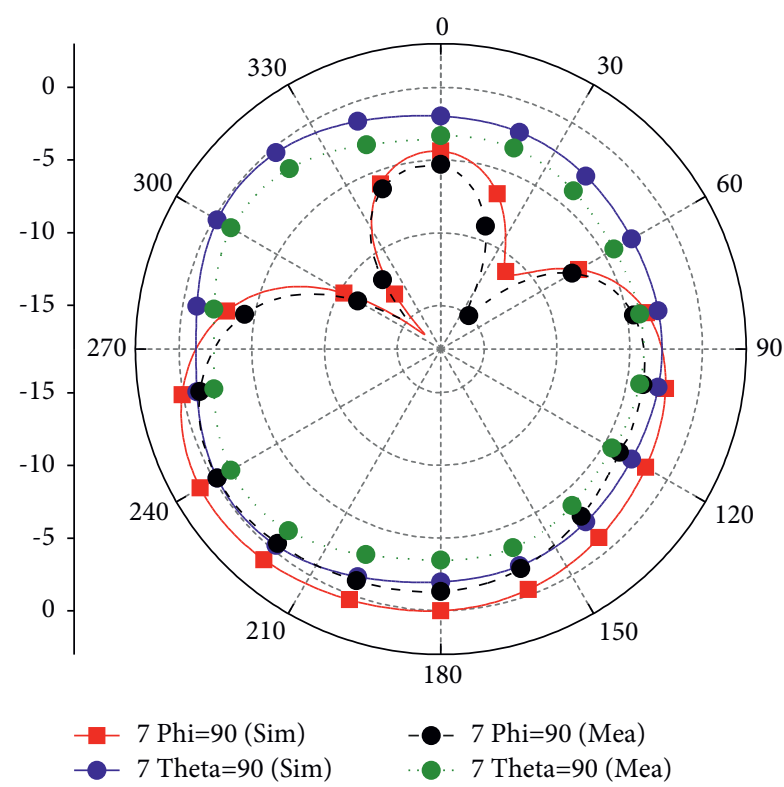

(d)

Figure 6: Radiation patterns. (a) $4.5 \mathrm{GHz}$. (b) $5.5 \mathrm{GHz}$. (c) $6 \mathrm{GHz}$. (d) $7 \mathrm{GHz}$.

proposed antenna shows satisfactory radiation pattern characteristics and exhibits response as required by UWB systems [11-14].

3.2. Surface Currents. Figure 7 shows the surface currents patterns at the resonance frequency of $4.5,5.5,6$, and $7 \mathrm{GHz}$. From the figure, the ground slot and plane can be observed, and the titled square frames are responsible for generating the resonances. The ground slot is helpful in generating the constructive interface of currents. Furthermore, in lower frequency values, the effect of the square flames can be seen forming constructive interface at the edges of the frames.

From Table 1, it can be seen that the proposed antenna is compact in size, and also, the gain throughout the frequency range is nearly flat. Also, the proposed antenna offers omnidirectional radiation characteristics. With this small 


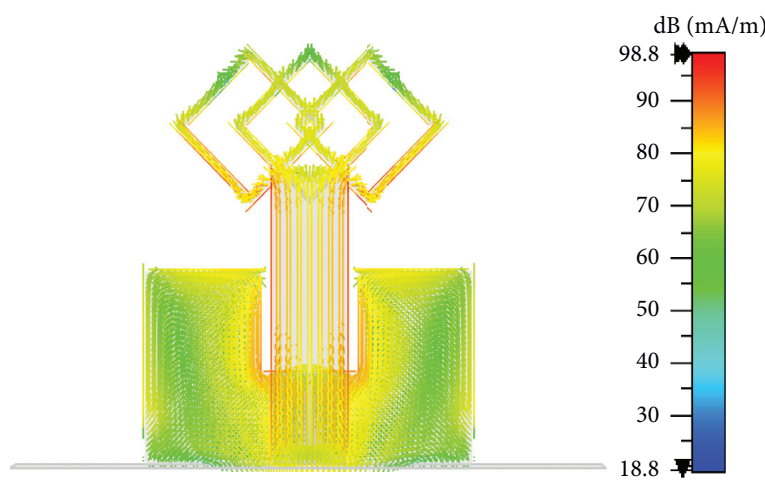

(a)

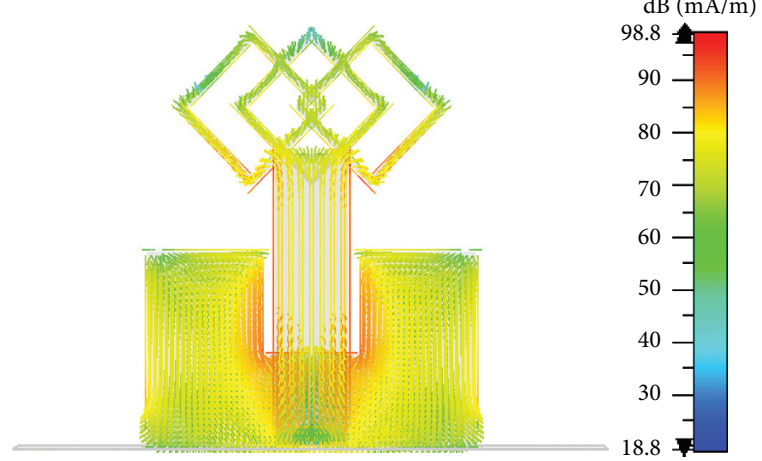

(c)

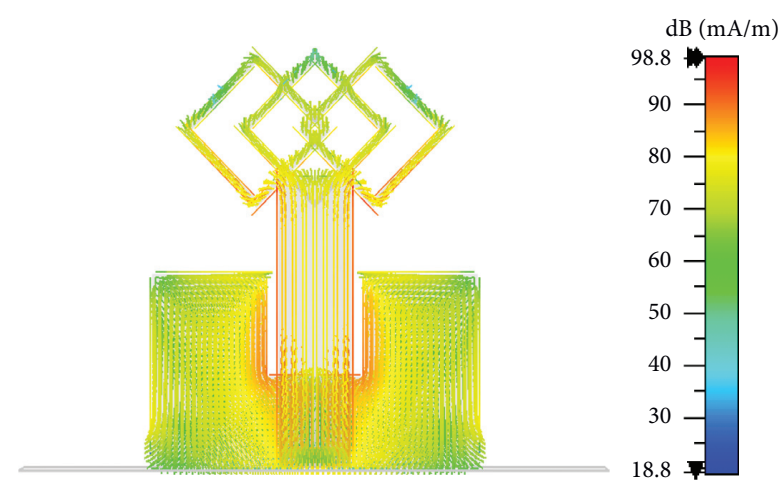

(b)

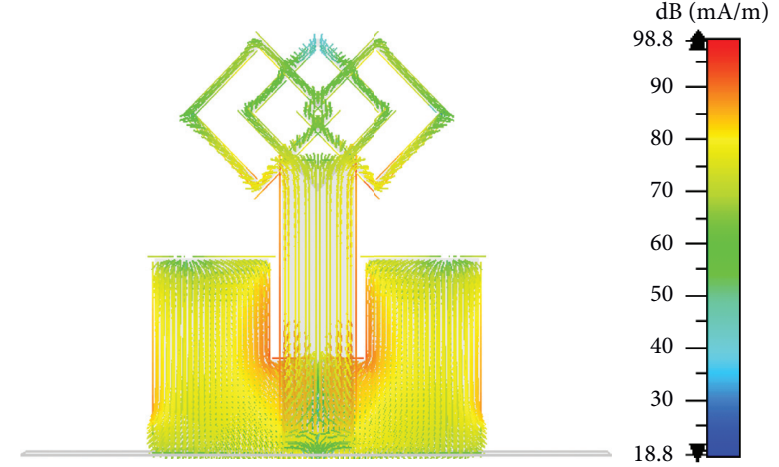

(d)

Figure 7: Surface current patterns. (a) $4.5 \mathrm{GHz}$. (b) $5.5 \mathrm{GHz}$. (c) $6 \mathrm{GHz}$. (d) $7 \mathrm{GHz}$.

TABLE 1: Comparison table of proposed antenna with published literature.

\begin{tabular}{lcccc}
\hline Reference & Frequency $(\mathrm{GHz})$ & Size $(\mathrm{L} \times \mathrm{W})$ & $\begin{array}{c}\text { Gain } \\
(\mathrm{dBi})\end{array}$ & Efficiency $(\%)$ \\
\hline$[5]$ & $3.4-8.0$ & $312 \times 121$ & 3.99 & 79 \\
{$[6]$} & $3.3-10.2$ & $31 \times 23$ & 4.1 & $\mathrm{~N} / \mathrm{A}$ \\
{$[9]$} & $3.25-8.85$ & $100 \times 160$ & 5.4 & 85 \\
{$[10]$} & $3.1-10.6$ & $25 \times 26$ & 3.83 & 76 \\
{$[11]$} & $2.5-12$ & $50 \times 50$ & $\mathrm{~N} / \mathrm{A}$ & $\mathrm{N} / \mathrm{A}$ \\
{$[12]$} & $3.2-10.6$ & $40 \times 40$ & 4.00 & 88 \\
{$[13]$} & $4.0-12.0$ & $50 \times 35$ & 5.25 & 75 \\
{$[14]$} & $3-14.5$ & $40 \times 34$ & 2.4 & 65 \\
{$[20]$} & $4.8-5.9$ & $30 \times 35$ & 5.3 & \\
{$[21]$} & $4.4-4.6 / 5.4-5.6$ & $26 \times 25$ & 4.89 & \\
{$[22]$} & $2.4 \times 3.6$ & $26.1 \times 25.4$ & 5.6 & \\
Proposed & $3.3-11.5$ & $14 \times 18$ & 1.4 & \\
\hline
\end{tabular}

size and robust characteristics, the reported literature can be termed as a compact and potential candidate for future wireless systems.

\section{Conclusion}

This research presents a novel three square tilted frame monopole antenna with a compact size. The proposed antenna is made with a square cut in the top middle section of the ground plane which helps in generating the wideband response from 3.3 to $11.6 \mathrm{GHz}$ frequency. The total size of the antenna is $14 \times 18 \times 1.6 \mathrm{~mm}^{3}$, which is quite small as compared to published literature. Through the performance parameters, the antenna is found to be exhibiting good response. Moreover, the proposed antenna is fabricated, and measured results are in well agreement with the simulated results which validate that the proposed antenna is a good contender for UWB applications. In future, this work can further be improved with MIMO configuration and through metasurfaces.

\section{Data Availability}

The data used to support the findings of this study are included within the article. 


\section{Conflicts of Interest}

The authors declare that they have no conflicts of interest.

\section{Acknowledgments}

This project was supported by the National Natural Science Foundation of China (61861043).

\section{References}

[1] D. A. Sehrai, M. Abdullah, A. Altaf et al., "A novel high gain wideband mimo antenna for $5 \mathrm{G}$ millimeter wave applications," Electronics, vol. 9, no. 6, p. 1031, 2020.

[2] C. R. Guo, W. J. Lu, Z. S. Zhang, and L. Zhu, "Wideband nontraveling-wave triple-mode slotline antenna," IET Microwaves, Antennas \& Propagation, vol. 11, no. 6, pp. 886-891, 2017.

[3] L. Wang, K. H. Teng, Y. Lian, and C. H. Heng, "A IR UWB timed-array radar based on 16-channel transmitter and sampling capacitor reused receiver," IEEE Transactions on Circuits and Systems II: Express Briefs, vol. 65, no. 7, pp. 878-882, 2018.

[4] S. Koziel, S. Ogurtsov, W. Zieniutycz, and A. Bekasiewicz, "Design of a planar UWB dipole antenna with an integrated balun using surrogate-based optimization," IEEE Antennas and Wireless Propagation Letters, vol. 14, pp. 366-369, 2015.

[5] J. Cruz, A. Serres, A. de Oliveira et al., "Bio-inspired printed monopole antenna applied to partial discharge detection," Sensors, vol. 19, no. 3, pp. 628-643, 2019.

[6] P. S. Bakariya, S. Dwari, and M. Sarkar, "Triple band notch UWB printed monopole antenna with enhanced bandwidth," AEU-International Journal of Electronics and Communications, vol. 69, no. 1, pp. 26-30, 2015.

[7] K. Nakprasit, A. Sakonkanapong, and C. Phongcharoenpanich, "Elliptical ring antenna excited by circular disc monopole for UWB communications," International Journal of Antennas and Propagation, vol. 2020, Article ID 8707182, 11 pages, 2020.

[8] M. Frank, F. Lurz, M. Kempf, J. Rober, and R. Weigel, "Miniaturized ultra-wideband antenna design for human implants," in Proceedings of the IEEE Radio and Wireless Symosium, pp. 48-51, San Antonio, TX, USA, January 2020.

[9] S. A. Omar, A. Iqbal, O. A. Saraereh, and A. Basir, "An array of M-shaped Vivaldi antennas for UWB applications," Progress In Electromagnetics Research Letters, vol. 68, pp. 67-72, 2017.

[10] N. Ahmad Jan, S. Hassan Kiani, F. Muhammad et al., "Vshaped monopole antenna with chichena itzia inspired defected ground structure for UWB applications," Computers, Materials \& Continua, vol. 65, no. 1, pp. 19-32, 2020.

[11] I. B. Vendik, A. Rusakov, K. Kanjanasit, J. Hong, and D. Filonov, "Ultrawideband (UWB) planar antenna with single-, dual-, and triple-band notched characteristic based on electric ring resonator," IEEE Antennas and Wireless Propagation Letters, vol. 16, pp. 1597-1600, 2017.

[12] F. Amin, R. Saleem, T. Shabbir, S. u. Rehman, M. Bilal, and M. F. Shafique, "A compact quad-element UWB-MIMO antenna system with parasitic decoupling mechanism," Applied Sciences, vol. 9, no. 11, p. 2371, 2019.

[13] R. Kumar, R. R. Krishna, and N. Kushwaha, "A fractal monopole antenna for UWB applications," in Proceedings of the IEEE Applied Electromagnetics Conference, pp. 1-2, Bhubaneswar, India, December 2013.
[14] C. Hua, Y. Lu, and T. Liu, "Printed UWB heart-shaped monopole antenna with band-notch reconfigurability," in Proceedings of the IEEE International Workshop on Electromagnetics: Applications and Student Innovation Competition, pp. 1-3, Nanjing, China, May 2016.

[15] W. A. Awan, A. Zaidi, N. Hussain, A. Iqbal, and A. Baghdad, "Stub loaded, low profile UWB antenna with independently controllable notch-bands," Microwave and Optical Technology Letters, vol. 61, no. 11, pp. 2447-2454, 2019.

[16] A. Iqbal, A. Smida, N. Mallat, M. Islam, and S. Kim, "A compact UWB antenna with independently controllable notch bands," Sensors, vol. 19, no. 6, p. 1411, 2019.

[17] A. Iqbal, O. A. Saraereh, and S. K. Jaiswal, "Maple leaf shaped UWB monopole antenna with dual band notch functionality," Progress In Electromagnetics Research C, vol. 71, pp. 169-175, 2017.

[18] A. Lalbakhsh, M. U. Afzal, K. P. Esselle, and S. L. Smith, "Wideband near-field correction of a fabry-perot resonator antenna," IEEE Transactions on Antennas and Propagation, vol. 67, no. 3, pp. 1975-1980, 2019.

[19] B. Mohamadzade, R. B. V. B. Simorangkir, R. M. Hashmi, and A. Lalbakhsh, "A conformal ultrawideband antenna with monopole-like radiation patterns," IEEE Transactions on Antennas and Propagation, vol. 68, no. 8, pp. 6383-6388, 2020.

[20] J. Iqbal, "Circularly polarized bandwidth enhancement using hollow cylindrical DRA," in Proceedings of the 2017 International Conference on Engineering Technology and Technopreneurship (ICE2T), pp. 1-4, Kuala Lumpur, Malayisa, September 2017.

[21] U. Illahi, M. I. Sulaiman, J. Iqbal, M. Alam, and M. S. Mazliham, "A novel singly fed wideband circularly polarized rectangular dielectric resonator antenna using hook-shaped metal strip," Sind University Research Journal, vol. 50, no. 3D, pp. 59-62, 2018.

[22] U. Illahi, J. Iqbal, M. Sulaiman, M. Alam, S. Mazliham, and H. Jamaluddin, "Circularly polarized rectangular dielectric resonator antenna excited by an off-set conformal metal strip," Indonesian Journal of Electrical Engineering and Computer Science, vol. 15, no. 2, pp. 902-909, 2019. 